\title{
Does knowledge of danger signs of pregnancy predict birth preparedness? A critique of the evidence from women admitted with pregnancy complications
}

Scovia N Mbalinda ${ }^{1}$, Annettee Nakimuli ${ }^{2}$, Othman Kakaire ${ }^{2}$, Michael O Osinde ${ }^{3}$, Nelson Kakande ${ }^{4}$ and Dan K Kaye ${ }^{2^{*}}$

\begin{abstract}
Background: Improved knowledge of obstetric danger signs, birth preparedness practices, and readiness for emergency complications are among the strategies aimed at both enhancing utilization of maternal health services and increasing access to skilled care during childbirth, particularly for women with obstetric complications. It is unclear whether knowledge of danger signs translates into improved birth preparedness and complication readiness. The objective was to assess the association between knowledge of danger signs and birth preparedness among women admitted with pregnancy complications.
\end{abstract}

Methods: The study included 810 women admitted in the antepartum period to Mulago hospital, Uganda. Data was collected on socio-demographic characteristics, reproductive history, pregnancy complications, knowledge of danger signs, and birth preparedness/complication readiness (BPCR). Logistic regression analyses were conducted to explore the relationship between knowledge of danger signs and birth preparedness.

Results: Only about 1 in 3 women were able to mention at least three of the five basic components of BPCR, and could be regarded as 'knowledgeable on BPCR'. One in every 4 women could not mention any of the five components. Women with history of obstetric problems during the previous pregnancy were more likely to be knowledgeable on danger signs when compared to those who had no complications in prior pregnancy. Women who were knowledgeable on danger signs were four times more likely to be knowledgeable on BPCR as compared to those who were not knowledgeable.

Conclusions: Though awareness about danger signs was low, knowledge of danger signs was associated with knowledge of birth preparedness. More emphasis should be given to emergency/complication readiness during antenatal care sessions. There is a need to strengthen existing policy interventions to address birth preparedness and complication readiness for obstetric emergencies.

Keywords: Pregnancy, Childbirth, Knowledge about danger signs, Birth preparedness, Complication readiness, Maternal near miss

\footnotetext{
* Correspondence: dankkaye@yahoo.com

${ }^{2}$ Department of Obstetrics and Gynecology, School of Medicine, College of

Health Sciences, Makerere University, P.O. Box 7072, Kampala, Uganda

Full list of author information is available at the end of the article
} 


\section{Background}

Childbirth is often associated with unpredictable lifethreatening obstetric complications that lead to maternal and neonatal morbidity and mortality, especially in lowresource countries [1]. Indeed, in the absence of skilled obstetric care, $15 \%$ of all pregnant women will suffer from serious and long term morbidities and disabilities [2]. Receiving care from a skilled provider during childbirth has been identified as the most important intervention to prevent maternal and neonatal mortality [3-5]. Improved knowledge of obstetric danger signs, birth preparedness practices, and readiness for emergency complications are among strategies aimed at both enhancing utilization of maternal health services and increasing access to skilled care during childbirth, particularly for women with obstetric complications [3-6].

The Ugandan Ministry of Health launched the Safe Motherhood Healthcare package in 2004 [7], with the ultimate goal of providing obstetric interventions to reduce maternal mortality. The causes of maternal morbidity and mortality may be analyzed using the Three Delays Model [8]. This model identifies three phases of delay: delay in seeking care, delay in reaching care, and delay in receiving adequate care when reaching a health facility [8]. This model is based on the assumptions that knowledge of danger signs and preparedness for addressing obstetric complications ensures that predictable elements of the three phases of delay can be anticipated, identified in time and addressed promptly as they arise [9]. Delays in seeking care may be caused by failure to recognize signs of complications or perceive the severity of illness, cost considerations, and previous negative experiences with the healthcare system. Delays in reaching care may be caused by the long distances from a woman's home to a health facility, poor condition of roads, and absence or unaffordability of emergency transportation. Delays in receiving care may result from negative attitudes of healthcare providers, shortages of supplies and basic equipment, a lack of healthcare personnel, and poor skills of healthcare providers.

The Maternal and Neonatal Health Program of JHPIEGO developed the birth-preparedness and complication readiness (BPCR) matrix to address these three delays at various levels to ensure that women and newborns receive appropriate, effective, and timely care [9]. These levels include the pregnant woman, her family, her community, health providers, health facilities, and policy-makers at different stages: pregnancy, childbirth, and the postpartum period. The concept of BPCR includes knowledge of danger signs, planning for a birth attendant and birth location, arranging transportation, identifying a blood donor, and saving money in case of an obstetric complication. It is unclear whether knowledge of danger signs translates into improved birth preparedness and complication readiness, yet the objective of the BPCR strategy is to promote active preparation and decision making for delivery by pregnant women and their families, as every pregnant woman faces risk of sudden and unpredictable life threatening complications. From studies in Ethiopia among pregnant women or women of reproductive age [10-12], most women were not knowledgeable about birth preparedness and complication readiness for obstetric emergencies, despite having awareness on the danger signs of pregnancy.

Studies performed in different countries have shown that health education during antenatal care enhances the utilization of skilled health care and improves mothers' knowledge about obstetric danger signs [13-18]. During antenatal care and any other contact with pregnant women, the health education provided is supposed to raise awareness about obstetric danger signs and ensure mothers make adequate preparation for childbirth complications. Whether knowledge of danger signs translates into and is associated with improved birth preparedness has not been documented. Such an assessment would add to the evidence that specific interventions result in reduced maternal or neonatal mortality and morbidity. The objective was to explore the association between knowledge of obstetric danger signs and birth preparedness/complication readiness among women admitted in pregnancy with obstetric complications.

\section{Methods}

\section{Study setting}

This research was part of a mixed-methods study assessing preventable factors associated with maternal and neonatal near-miss morbidity, from the perspective of patients and healthcare providers. The study was conducted at Mulago hospital, Uganda's national referral hospital and the teaching hospital for Makerere University. It has over 1,500 beds, of which over 400 are maternity beds, and conducts over 35,000 deliveries per year.

\section{Participants and data collection}

Participants were women consecutively admitted to hospital from 20 to 36 weeks of gestation for complications of pregnancy and all women with pregnancy complications were eligible for inclusion into the study. The main reason for admission was febrile illness (34\%). Others were anemia, hypertensive disorders, preterm labor, false labor, urinary tract infections, and anemia in pregnancy. Data was collected as an exit interview after hospital discharge using the tool on monitoring birth preparedness from JHIPIEGO [16]. This tool is used to guide assessment and monitoring of safe motherhood programs by evaluating interventions at multiple levels by identifying indicators, referred to as the BPCR Index, for each of six levels: the individual woman, her family (husband/partner), the community, the health facility, the provider, 
and the policymaker [19]. This tool is used to derive these indicators and in tracking progress (extent to which the indicators have been realized). The behaviors or practices identified by the tool are also labelled 'process indicators', because they measure processes along the pathway to maternal death or survival [20]. The tool was adapted to the local context of a hospital by eliminating the policy maker component of the instrument.

The data collected included socio-demographic characteristics such as age, marital status, level of education and occupation, number of pregnancies, number of deliveries, any abortions, number of living children, gestation age of the current pregnancy (obtained from a combination of the last normal menstrual period, the fundal height on abdominal palpation, and abdominal ultrasound examination). Other data included obstetric complications during the current and previous pregnancies. Women were asked to spontaneously cite six danger signs during pregnancy, childbirth, and immediate postpartum period, as well as two danger signs for newborns; these were open-ended questions. A woman who reported at least one danger sign in pregnancy, childbirth or postpartum period was considered to be 'knowledgeable' on danger signs. We also asked about awareness components of BPCR. Women who mentioned at least three of the five basic components of BPCR were regarded as 'knowledgeable' on BPCR.

\section{Data analysis}

Data was entered and analyzed by using SPSS windows version 16. We compared the proportion of women who were knowledgeable about danger signs with knowledge on BPCR. The independent variables included sociodemographic characteristics, reproductive history, pregnancy complications, and being knowledgeable about danger signs (knowledge of at least one antepartum, intrapartum, and postpartum danger sign), while the independent variable was being knowledgeable on BPCR. Variables with a $P$ value of $<0.2$ were further analyzed using the logistic regression analysis to assess factors independently associated with knowledge about BPCR.

\section{Ethical considerations}

Ethical approval to conduct the study was obtained from the Ethics and research committees of Mulago hospital (REC 310-2012), the School of Medicine, Makerere University College of Health Sciences (REC 2012-172) and Uganda National Council for Science and Technology. Permission to conduct the study was obtained from the department of Obstetrics and Gynecology, Makerere University. All participants gave written informed consent to be interviewed.

\section{Results}

Table 1 shows the socio-demographic characteristics. All the women had attended antenatal care at least three times prior to hospitalization. The mean age of the participants was $25.4 \pm 6$ years (median 25 years). The majority were of gravidity 2 to 4 . Table 2 shows the knowledge on danger signs. Vaginal bleeding during pregnancy was the most commonly mentioned danger sign. Others were vaginal discharge, abdominal pain, and fever. Only $20 \%$ mentioned at least three danger signs and were regarded as knowledgeable.

Table 3 shows the knowledge and practices on birth preparedness and complication readiness, where multiple responses were elicited. More than 2 of every 3 women identified that saving money in case of emergency or during labor is an important component of

Table 1 Socio-demographic and obstetric characteristics of the study population

\begin{tabular}{|c|c|c|}
\hline Variables & $\mathrm{n}=810$ & $\%$ \\
\hline \multicolumn{3}{|l|}{ Age } \\
\hline$\leq 25$ & 732 & 90.4 \\
\hline$>25$ & 78 & 9.6 \\
\hline \multicolumn{3}{|l|}{ Education level } \\
\hline Primary or no formal education & 512 & 63.2 \\
\hline Secondary or higher level education & 298 & 36.8 \\
\hline \multicolumn{3}{|l|}{ Marital status } \\
\hline Single & 110 & 13.6 \\
\hline Married & 700 & 86.4 \\
\hline \multicolumn{3}{|l|}{ Occupation } \\
\hline Employed & 192 & 23.7 \\
\hline Not employed & 618 & 76.3 \\
\hline \multicolumn{3}{|l|}{ Gravidity } \\
\hline 1 & 212 & 26.2 \\
\hline $2-4$ & 438 & 57.8 \\
\hline$\geq 5$ & 130 & 16 \\
\hline \multicolumn{3}{|l|}{ Gestation age (wks) } \\
\hline$<37$ & 740 & 91.1 \\
\hline$\geq 37$ & 70 & 8.9 \\
\hline \multicolumn{3}{|l|}{ Antenatal attendance } \\
\hline Attendance at least 4 times & 535 & 66.0 \\
\hline Attended 1-2 times & 245 & 30.2 \\
\hline Never attended & 30 & 3.8 \\
\hline \multicolumn{3}{|c|}{ Previous obstetric complication in this pregnancy } \\
\hline Yes & 150 & 18.5 \\
\hline No & 660 & 81.5 \\
\hline \multicolumn{3}{|c|}{ Complication in a prior pregnancy $(n=568$ ) } \\
\hline Yes & 218 & 38.4 \\
\hline No & 350 & 61.6 \\
\hline
\end{tabular}


Table 2 Knowledge on obstetric danger signs, where multiple responses were elicited

\begin{tabular}{|c|c|c|}
\hline Danger sign reported & Numbers & $\%$ \\
\hline \multicolumn{3}{|l|}{ *During pregnancy } \\
\hline Vaginal bleeding & 546 & 67.4 \\
\hline Swollen hands, face, or both & 376 & 46.4 \\
\hline Blurred vision & 48 & 5.9 \\
\hline Abdominal pain & 62 & 7.7 \\
\hline Fever & 46 & 5.2 \\
\hline Severe headache & 51 & 6.3 \\
\hline \multicolumn{3}{|l|}{ *During labor and delivery } \\
\hline Profuse vaginal bleeding & 92 & 11.4 \\
\hline Prolonged labor longer than 12 hrs & 12 & 1.5 \\
\hline Convulsions & 4 & 0.5 \\
\hline Retained placenta & 6 & 0.7 \\
\hline Generalized weakness or collapse & 22 & 2.7 \\
\hline \multicolumn{3}{|l|}{ *Postpartum } \\
\hline Severe vaginal bleeding & 220 & 27.1 \\
\hline Foul smelling vaginal discharge & 152 & 18.7 \\
\hline High fever & 82 & 10.1 \\
\hline Abdominal pain & 56 & 6.9 \\
\hline \multicolumn{3}{|l|}{$\begin{array}{l}\text { **Knowledge of three danger signs } \\
\text { (at least at each stage) }\end{array}$} \\
\hline Yes & 225 & 27.8 \\
\hline No & 585 & 72.2 \\
\hline
\end{tabular}

BPCR. However, only about 1 in every 4 women mentioned the need to identify means of transport, while only about 1 in 8 women mentioned the need to identify a blood donor. With these findings, only $36.5 \%$ of the respondents were regarded as knowledgeable on BPCR. While nearly 1 in every 3 women mentioned at least three components of BPCR, about 1 in every 4 women could not mention any of the five components.
Table 4 shows factors associated with knowledge of danger signs while Table 5 shows factors associated with knowledge of BPCR. There was a statistically significant association between not being in formal employment and lack of knowledge on BPCR (adjusted odds ratio, 0.4; 95\% CI, 0.2-0.8). There was a significant association, however, between knowledge of danger signs (during pregnancy, labor and postpartum period) and BPCR (adjusted odds ratio, 3.9; 95\% CI, 2.0-7.5).

\section{Discussion}

The study showed low levels of knowledge of obstetric danger signs and low levels of birth preparedness among women with pregnancy complications during the antepartum period. Only about 1 in 3 women were able to mention at least two of the five basic components of BPCR, and could be regarded as 'knowledgeable for BPCR'. Women who were knowledgeable on danger signs were four times more likely to be knowledgeable on BPCR as compared to those who were not knowledgeable. Knowledge of at least three danger signs was independently associated with knowledge about BPCR.

The BPCR concept is based on the assumption that knowledge of danger signs leads to greater anticipation and preparation to mitigate effects of pregnancy and childbirth complications by reducing the first two delays and the third delay if health facilities are prepared to address obstetric complications. Recognition of obstetric danger signs is the key factor in seeking health care for obstetric emergencies and seeking preventive care or health promotion during pregnancy and childbirth. Therefore, a lack of awareness of obstetric danger signs is associated with a lack of preparedness for normal birth or complication readiness in case of obstetric complications that require emergency healthcare $[5,6]$. With the assumption that 'every pregnancy faces risks', women should be made aware of danger signs of obstetric complications during pregnancy, childbirth, and the postpartum period. This empowers them to make

Table 3 Knowledge on the components of birth preparedness/complication readiness (BPCR)

\begin{tabular}{lll}
\hline Variables & Number \\
\hline *Basic component of BPCR & 544 \\
Saving money for use in emergencies or during labor & 194 \\
Preparations for place of birth & 216 & 67.2 \\
Identifying transport in case of emergency and during labor & 40 & 3.6 \\
Identifying a birth companion & 30 & 3.0 \\
Identifying a blood donor & 3.7 \\
Knowledge of three basic components of BPCR & 256 \\
Yes & 36.5 \\
No & 314 \\
\hline
\end{tabular}

*Multiple responses elicited. 
Table 4 Factors associated with being knowledgeable about three danger signs $(\mathbf{n}=\mathbf{8 1 0})$

\begin{tabular}{|c|c|c|c|c|c|}
\hline Variables & $\begin{array}{l}\text { Total } \\
\mathrm{n}=\mathbf{8 1 0}\end{array}$ & $\begin{array}{l}\text { Knowledgeable } \\
n=160\end{array}$ & $\%$ & $\begin{array}{l}\text { Univariate } \\
\text { OR }(95 \% \mathrm{Cl}) \\
\end{array}$ & $\begin{array}{l}\text { Multivariate } \\
\text { OR }(95 \% \mathrm{Cl}) \\
\end{array}$ \\
\hline \multicolumn{6}{|l|}{ Age } \\
\hline$\leq 25$ & 732 & 14,2 & 19.4 & 1 & 1 \\
\hline$>25$ & 78 & 1,8 & 23.1 & $1.2(0.5-2.7)$ & $1.3(0.4-3.7)$ \\
\hline \multicolumn{6}{|l|}{ Education level } \\
\hline Primary or no formal education & 298 & 6,0 & 20.1 & 1 & 1 \\
\hline Secondary or higher level of education & 512 & 1,00 & 19.5 & $1.1(0.7-1.7)$ & $1.9(0.9-4.0)$ \\
\hline \multicolumn{6}{|l|}{ Marital status } \\
\hline Married & 700 & 12,6 & 18.0 & 1 & 1 \\
\hline Single & 110 & 3,4 & 30.9 & $2.0(1.1-3.8)$ & $0.7(0.3-2.1)$ \\
\hline \multicolumn{6}{|l|}{ Occupation } \\
\hline Employed & 192 & 4,4 & 22.9 & 1 & 1 \\
\hline Not employed & 618 & 11,6 & 18.8 & $0.8(0.4-1.3)$ & $0.4(0.2-0.8)$ \\
\hline \multicolumn{6}{|l|}{ Parity } \\
\hline$<4$ & 698 & 13,2 & 18.9 & 1 & 1 \\
\hline$\geq 4$ & 112 & 2,8 & 25.0 & $1.4(0.7-2.7)$ & $1.2(0.5-2.9)$ \\
\hline \multicolumn{6}{|l|}{ Gestation age } \\
\hline$\geq 37$ & 72 & 1,2 & 16.7 & 1 & 1 \\
\hline$<37$ & 738 & 14,8 & 20.1 & $1.2(0.5-3.2)$ & $1.9(0.6-6.6)$ \\
\hline \multicolumn{6}{|l|}{ *Previous obstetric complication } \\
\hline Yes & 150 & 7,8 & 17.9 & 1 & 1 \\
\hline No & 660 & 4,0 & 26.7 & $0.28(0.23-0.34)$ & $0.2(0.14-0.41)$ \\
\hline
\end{tabular}

*Primigravida are excluded.

prompt decisions for healthcare seeking in case of routine healthcare seeking or emergency complications.

The findings are in agreement with previous research $[5,7,10-18]$ that shows that birth preparedness is not easy to achieve especially in developing countries, where the majority are relatively poor, few women identify transportation ahead of childbirth, few women put aside funds for transport in case of emergency, and few women are knowledgeable on danger signs or implement BPCR. This could be due to several factors [21-28]: poor antenatal care attendance, poor quality of health education during antenatal care, limited time available for antenatal care, lack of health education in hospitalized patients, rural poverty, absence of a functional referral system, and failure of the health system to implement the policy on BPCR.

Despite a limitation of being a hospital-based study, our findings raise several concerns. Firstly, while it is expected that most women hospitalized for pregnancy complications are aware of danger signs (since health education is supposed to be provided to them hospital during their hospitalization), this is not the case. The findings thus depict missed opportunities for health education during antenatal care and antepartum hospitalization. Such missed opportunities may be due to several problems such as understaffing and poor counseling (that would enable risk factor-recognition and birth preparedness) [29]. Secondly, BPCR should be made an integral part of maternal and child health services, and every opportunity should be utilized to ensure that women are informed about danger signs, the important danger signs, the implications of danger signs for safe motherhood, and what should be done to address obstetric complications. Sadly, this is not the case. Thirdly, efforts should be made to raise community awareness about birth preparedness, such as provision of emergency funds, emergency transport, and blood donors, and interventions that can be instituted at community level. Lastly, using the mass media to communicate information on danger signs might increase community awareness on birth preparedness and complication readiness for obstetric emergencies [30] through advocating for changes in attitudes, normative beliefs, and behaviors.

The implications of the findings are that interventions geared to improvement in complication readiness need to focus on raising public awareness on danger signs, and every opportunity, including hospitalization, must be utilized for health education on BPCR. Family members, particularly spouses, are keen on supporting women in developing birth plans and preparedness for birth as well as complication readiness for obstetric emergencies 
Table 5 Factors associated with being knowledgeable on birth preparedness/complication readiness $(B P C R)(n=810)$

\begin{tabular}{|c|c|c|c|c|c|}
\hline Variables & $\begin{array}{l}\text { Total } \\
\mathrm{n}=810\end{array}$ & $\begin{array}{l}\text { Knowledgeable } \\
\mathrm{n}=\mathbf{2 9 6}\end{array}$ & $\%$ & $\begin{array}{l}\text { Univariate } \\
\text { OR }(95 \% \mathrm{Cl})\end{array}$ & $\begin{array}{l}\text { Multivariate } \\
\text { OR }(95 \% \mathrm{Cl}) \\
\end{array}$ \\
\hline \multicolumn{6}{|l|}{ Age } \\
\hline$\leq 25$ & 732 & 266 & 36.3 & 1 & 1 \\
\hline$>25$ & 78 & 30 & 38.5 & $1.1(0.6-2.2)$ & $1.5(0.5-4.2)$ \\
\hline \multicolumn{6}{|l|}{ Education level } \\
\hline Primary or no formal education & 298 & 112 & 37.6 & 1 & 1 \\
\hline Secondary or higher level of education & 512 & 184 & 35.9 & $0.9(0.6-1.4)$ & $1.3(0.7-2.6)$ \\
\hline \multicolumn{6}{|l|}{ Marital status } \\
\hline Married & 700 & 218 & 31.1 & 1 & 1 \\
\hline Single & 110 & 78 & 70.9 & $0.23(0.15-0.33)$ & $0.43(0.52-0.64)$ \\
\hline \multicolumn{6}{|l|}{ Occupation } \\
\hline Employed & 192 & 90 & 46.9 & 1 & 1 \\
\hline Not employed & 618 & 206 & 33.3 & $0.5(0.4-0.9)$ & $0.3(0.2-0.6)$ \\
\hline \multicolumn{6}{|l|}{ Parity } \\
\hline$<4$ & 698 & 264 & 37.8 & 1 & 1 \\
\hline$\geq 4$ & 112 & 32 & 28.6 & $0.6(0.3-1.2)$ & $0.5(0.2-1.2)$ \\
\hline \multicolumn{6}{|l|}{ Gestation age (wks) } \\
\hline$\geq 36$ & 72 & 36 & 52.8 & 1 & 1 \\
\hline$<36$ & 738 & 260 & 35.0 & $0.5(0.2-0.9)$ & $0.2(0.1-0.5)$ \\
\hline \multicolumn{6}{|c|}{ Knowledge of danger signs during pregnancy } \\
\hline No & 660 & 102 & 63.8 & $2.3(2.3-2.7)$ & $3.9(2.0-7.5)$ \\
\hline Yes & 150 & 194 & 29.8 & 1 & 1 \\
\hline
\end{tabular}

$[18,31,32]$. This is critical as knowledge of danger signs is a prerequisite for prompt decision-making for childbirth, emergency obstetric complications and seeking referral [33-36]. Emphasis should be given to the quality of information offered to pregnant women during antenatal care $[37,38]$. While the emergency system has several components, it needs all of them to function adequately in order to maintain and sustain the 'emergency chain of care' [39]. Recognition that there is an emergency need is the primary step $[39,40]$. The next step is community support that involves effective communication, reliable transport, adequately functioning and equipped health facilities for first aid, and community funding [39-41]. The last step is a referral facility with appropriately trained, skilled, and equipped staff who can provide prompt effective treatment and referral to a higher level facility if necessary [31]. The three components must be maintained in a state of readiness.

\section{Conclusions}

The study shows low awareness of danger signs and birth preparedness among pregnant women admitted with pregnancy complications, which indicates a missed opportunity for health education. This makes informed decision-making problematic for pregnant women and healthcare providers.
However, women who were knowledgeable about danger signs were more knowledgeable about BPCR. New strategies are needed to inform pregnant women about BPCR so as to improve decision-making in pregnancy and childbirth. This calls for urgent need to utilize all available opportunities to raise awareness of obstetric danger signs and to strengthen health education and counseling on BPCR.

\section{Abbreviation}

BPCR: Birth-preparedness and complication readiness.

\section{Competing interests}

The authors declare that they have no competing interests.

\section{Authors' contributions}

DKK conceptualized the study. OK, MOO, and NK advised on the design. DKK collected the data, led the analysis, and wrote the text of the paper. All the co-authors gave advice on the presentation of the results. All co-authors reviewed and approved the final manuscript.

\section{Acknowledgements}

This study was part of a post-doctoral research funded by SIDA through the Makerere University-Karolinska Institutet postdoctoral research grants. The conclusions are those of the authors and do not necessarily represent views of the funders, Mulago Hospital, or Makerere University. We are grateful to all women who participated in this study.

\section{Author details}

${ }^{1}$ Department of Nursing, School of Health Sciences, College of Health Sciences, Makerere University, P.O. Box 7072, Kampala, Uganda. ${ }^{2}$ Department of Obstetrics and Gynecology, School of Medicine, College of Health 
Sciences, Makerere University, P.O. Box 7072, Kampala, Uganda. ${ }^{3}$ Department of Obstetrics and Gynecology, Jinja Regional Hospital, Jinja, Uganda. ${ }^{4} \mathrm{Clinical}$, Operations and Health Services Research Program, Joint Clinical Research Centre, P. O. Box 10005, Kampala, Uganda.

Received: 26 February 2014 Accepted: 29 September 2014 Published: 9 October 2014

\section{References}

1. Moran AC, Sangli G, Dineen R, Rawlins B, Yaméogo M, Baya B: Birthpreparedness for maternal health: findings from Koupéla District, Burkina Faso. J Health Popul Nutr 2006, 24(4):489-497.

2. WHO: Maternal Mortality in 2000: Estimates Developed by WHO, UNICEF and UNFPA. Geneva: World Health Organization; 2004.

3. Hussein J, Kanguru L, Astin M, Munjanja S: The effectiveness of emergency obstetric referral interventions in developing country settings: a systematic review. PLoS Med 2012, 9(7):e1001264.

4. Paxton A, Maine D, Freedman L, Fry D, Lobis S: The evidence for emergency obstetric care. Int J Gynaecol Obstet 2005, 88(2):181-193.

5. Graham W, Themmen E, Bassane B, Meda N, De Brouwere V: Evaluating skilled care at delivery in Burkina Faso: principles and practice. Trop Med Int Health 2008, 13(Suppl 1):6-13.

6. Pembe $A B$, Carlstedt A, Urassa DP, Lindmark G, Nystrom L, Darj E: Effectiveness of maternal referral system in a rural setting: a case study from Rufiji district, Tanzania. BMC Health Serv Res 2010, 10:326.

7. The Ministry of Heath Uganda: Health Sector Strategic Plan 2010/11-2014/15. http://www.health.go.ug/docs/HSSP_III_2010.pdf Accessed 10 February 2014.

8. Thaddeus S, Maine D: Too far to walk: maternal mortality in context. Soc Sci Med 1994, 38:1091-1110.

9. JHIPEGO; Maternal and Neonatal Health (MNH) Program: Birth Preparedness and Complication Readiness: A Matrix of Shared Responsibilities. 2001. http:// www.jhpiego.org/files/bpcrmatrix.pdf.

10. Markos D, Bogale D: Birth preparedness and complication readiness among women of child bearing age group in Goba woreda, Oromia region, Ethiopia. BMC Pregnancy Childbirth 2014, 14(1):282.

11. Tura G, Afework MF, Yalew AW: The effect of birth preparedness and complication readiness on skilled care use: a prospective follow-up study in Southwest Ethiopia. Reprod Health 2014, 11:60.

12. Kaso M, Addisse M: Birth preparedness and complication readiness in Robe Woreda, Arsi Zone, Oromia Region, Central Ethiopia: a crosssectional study. Reprod Health 2014, 11:55.

13. Pembe AB, Urassa DP, Carlstedt A, Lindmark G, Nystrom L, Darj E: Rural Tanzanian women's awareness of danger signs of obstetric complications. BMC Pregnancy Childbirth 2009, 9:12.

14. Kabakyenga JK, Östergren PO, Turyakira E, Pettersson KO: Knowledge of obstetric danger signs and birth preparedness practices among women in rural Uganda. Reprod Health 2011, 8:33.

15. Mulogo EM, Witte K, Bajunirwe F, Nabukera SK, Muchunguzi C, Batwala VK, Bagenda F, Farr C, Barry S: Birth plans and health facility based delivery in rural Uganda. East Afr Med J 2006, 83(3):74-83.

16. Magoma M, Requejo J, Campbell OM, Cousens S, Filippi V: High ANC coverage and low skilled attendance in a rural Tanzanian district: a case for implementing a birth plan intervention. BMC Pregnancy Childbirth 2010, 10:13

17. Mutiso SM, Qureshi Z, Kinuthia J: Birth preparedness among antenatal clients. East Afr Med J 2008, 85(6):275-283.

18. Kakaire O, Kaye DK, Osinde MO: Male involvement in birth preparedness and complication readiness for emergency obstetric referrals in rural Uganda. Reprod Health 2011, 8:12

19. JHPIEGO: Monitoring Birth Preparedness and Complication Readiness: Tools and Indicators for Maternal and Newborn Health. Baltimore, MD: JHPIEGO; 2004:1-19.

20. Stanton CK: Methodological issues in the measurement of birth preparedness in support of safe motherhood. Eval Rev 2004 28(3):179-200

21. Magoma M, Requejo J, Merialdi M, Campbell OM, Cousens S, Filippi V: How much time is available for antenatal care consultations? Assessment of the quality of care in rural Tanzania. BMC Pregnancy Childbirth 2011, 11:64.
22. Hailu M, Gebremariam A, Alemseged F, Deribe K: Birth preparedness and complication readiness among pregnant women in Southern Ethiopia. PLoS One 2011, 6(6):e21432

23. Onayade AA, Akanbi OO, Okunola HA, Oyeniyi CF, Togun OO, Sule SS: Birth preparedness and emergency readiness plans of antenatal clinic attendees in Ile-ife, Nigeria. Niger Postgrad Med J 2010, 17(1):30-39.

24. Ekabua JE, Ekabua KJ, Odusolu P, Agan TU, Iklaki CU, Etokidem AJ: Awareness of birth preparedness and complication readiness in southeastern Nigeria. ISRN Obstet Gynecol 2011, 2011:560641.

25. McDonagh $\mathrm{M}$ : Is antenatal care effective in reducing maternal morbidity and mortality? Health Policy Plan 1996, 11(1):1-15.

26. Agarwal S, Sethi V, Srivastava K, Jha PK, Baqui AH: Birth preparedness and complication readiness among slum women in Indore city, India. J Health Popul Nutr 2010, 28(4):383-391.

27. Mrisho M, Schellenberg JA, Mushi AK, Obrist B, Mshinda H, Tanner M, Schellenberg D: Factors affecting home delivery in rural Tanzania. Trop Med Int Health 2007, 12(7):862-872.

28. Iliyasu Z, Abubakar IS, Galadanci HS, Aliyu MH: Birth preparedness, complication readiness and fathers' participation in maternity care in a northern Nigerian community. Afr J Reprod Health 2010, 14(1):21-32.

29. Tetui M, Ekirapa EK, Bua J, Mutebi A, Tweheyo R, Waiswa P: Quality of Antenatal care services in eastern Uganda: implications for interventions. Pan Afr Med J 2012, 13:27.

30. Asp G, Odberg Pettersson K, Sandberg J, Kabakyenga J, Agardh A: Associations between mass media exposure and birth preparedness among women in southwestern Uganda: a community-based survey. Glob Health Action 2014, 7:22904.

31. Aarnio P, Chipeta E, Kulmala T: Men's perceptions of delivery care in rural Malawi: exploring community level barriers to improving maternal health. Health Care Women Int 2013, 34(6):419-439.

32. Kaye DK, Kakaire O, Nakimuli A, Osinde MO, Mbalinda SN, Kakande N: Male involvement during pregnancy and childbirth: men's perceptions, practices and experiences during the care for women who developed childbirth complications in Mulago Hospital, Uganda. BMC Pregnancy Childbirth 2014, 14(1):54.

33. McPherson RA, Khadka N, Moore JM, Sharma M: Are birth preparedness programmes effective? Results from a field trial in Siraha district, Nepal. $J$ Health Popul Nutr 2006, 24:479-488.

34. Aboud FE, Singla DR: Challenges to changing health behaviours in developing countries: a critical overview. Soc Sci Med 2012, 75:589-594

35. Mpembeni RN, Killewo JZ, Leshabari MT, Massawe SN, Jahn A, Mushi D, Mwakipa H: Use pattern of maternal health services and determinants of skilled care during delivery in Southern Tanzania: implications for achievement of MDG-5 targets. BMC Pregnancy Childbirth 2007, 7:29.

36. MCFarlin BL: Elective cesarean birth: issues and ethics of an informed decision. J Midwifery Womens Health 2004, 49:421-429.

37. Little MO, Lyerly AD, Mitchell LM, Armstrong EM, Harris LH, Kukla R, Kuppermann M: Mode of delivery: toward responsible inclusion of patient preferences. Obstet Gynecol 2008, 112(4):913-918.

38. Thompson R, Miller YD: Birth control: to what extent do women report being informed and involved in decisions about pregnancy and birth procedures? BMC Pregnancy Childbirth 2014, 14(1):62.

39. Essendi $\mathrm{H}$, Mills $\mathrm{S}$, Fotso J-C: Barriers to formal emergency obstetric care services' utilization. J Urban Health 2011, 88(Suppl 2):356-369.

40. Cole-Ceesay R, Cherian M, Sonko A, Shivute N, Cham M, Davis M, Fatty M, Wieteska S, Baro M, Watson D, Phillips B, Macdonald R, Hayden B, Southall $D$ : Strengthening the emergency healthcare system for mothers and children in the Gambia. Reprod Health 2010, 7:21.

41. Lee ACC, Lawn JE, Cousens S, Kumar V, Osrin D, Bhutta ZA, Wall SN, Nandakumar AK, Syed U, Darmstadt GL: Linking families and facilities for care at birth: What works to avert intrapartum-related deaths? Int $J$ Gynaecol Obstet 2009, 107(Suppl 1):S65-S88.

\section{doi:10.1186/1478-4505-12-60}

Cite this article as: Mbalinda et al:: Does knowledge of danger signs of pregnancy predict birth preparedness? A critique of the evidence from women admitted with pregnancy complications. Health Research Policy and Systems 2014 12:60 